\title{
Analisis Kesalahan Mahasiswa dalam Menyajikan Representasi Visual Data Statistik pada Mata Kuliah Biostatistika
}

\author{
Ayunda Sri Wahyuningrum ${ }^{1^{*}}$ \\ ${ }^{1}$ Fakultas MIPA, Prodi Pendidikan Biologi, Universitas Indraprasta PGRI \\ *email: ayunda.sriwahyuningrum@unindra.ac.id
}

\section{Article History \\ Received: \\ 20/09/2020 \\ Revised: \\ 1/10/2020 \\ Accepted: \\ 15/11/2020 \\ Kata kunci: \\ Biostatistika \\ Data statistik \\ Diagram grafik \\ Representasi \\ visual}

Keywords:

Biostatistics

Data statistic

Graphic

diagram

Visual

representation

\begin{abstract}
ABSTRAK
Banyak penelitian mengungkapkan bahwa pemahaman statistik di sekolah mempengaruhi pemahaman dalam mempelajari statistika di perguruan tinggi. Penelitian ini bertujuan untuk menyelidiki pemahaman mahasiswa program studi Pendidikan Biologi dalam menyajikan representasi visual dari data statistik pada mata kuliah Biostatistika melalui jenis-jenis kesalahan yang terjadi. Penelitian ini merupakan penelitian kualitatif deskriptif yang dilaksanakan kepada 79 mahasiswa di salah satu universitas di Jakarta. Data dikumpulkan dari hasil jawaban mereka dalam menyajikan data statistik yang berkenaan dengan pembelajaran biologi. Hasil penelitian ini mengungkapkan bahwa ada beberapa jenis kesalahan yang dilakukan, yakni kesalahan dalam memberikan keterangan atau menyampaikan informasi, kesalahan dalam memahami konsep matematis yang ada pada grafik, kesalahan memaknai bilangan yang tercantum pada grafik, dan kesalahan memilih grafik yang sesuai dengan tujuan penyajian data. Temuan ini diharapkan dapat memperbaiki cara guru dan dosen mengajarkan statistika deskriptif sehingga kesalahan-kesalahan tersebut dapat dihindari atau diminimalisasi, khususnya pada ruang lingkup penelitian di bidang biologi murni dan pendidikan biologi.
\end{abstract}

Copyright (C) 2021 LPPM Universitas Indraprasta PGRI. All Right Reserved

\section{PENDAHULUAN}

Biostatistika merupakan salah satu cabang ilmu yang menunjukkan bahwa statistika digunakan atau diterapkan pada penelitianpenelitian di bidang kependidikan biologi, biologi murni, maupun medis. Ilmu ini banyak diterapkan pada penelitian di dunia kesehatan (Hayat et al., 2017; Lachenbruch, 2011; Oster et al., 2020), pembelajaran biologi di sekolah maupun perguruan tinggi (Loux et al., 2016; Hidayat, 2018; McGreevy \& Church, 2020), atau penelitian yang berkaitan dengan alam (Soraggi et al., 2018; Panzeri et al., 2017; Rivest \& Duchesne, 2016; Brown et al., 2016). 
Penerapan statistik dalam ruang lingkup penelitian tersebut selanjutnya menjadi pemahaman yang harus dikuasai oleh mahasiswa sehingga biostatistika dijadikan sebagai salah satu mata kuliah wajib. Pembelajaran biostatistika bertujuan agar mahasiswa mampu menerapkan statistik dengan tepat dan memahami pentingnya teknis statistik dalam kegiatan meneliti. Mahasiswa perlu memahami cara untuk menangani data, mulai dari mengidentifikasi suatu masalah, mengumpulkan dan mengolah data yang diperlukan, menyajikan data, menganalisis, hingga menginterpretasikan data tersebut (Hasan, 2012; McGrath, 2014).

Berkenaan dengan penerapan statistik dalam suatu penelitian ilmiah, pemahaman tentang statistik deskriptif merupakan pemahaman dasar yang perlu dikuasai oleh mahasiswa sebelum memasuki prosedur-prosedur dalam menarik kesimpulan (Siegel, 1986; Sugiyono, 2017; Sayeg-Sánchez \& Rodríguez-Paz, 2020). Statistik deskriptif tersebut meliputi cara untuk menyajikan data yang berupa tabel atau grafik, pengukuran gejala pusat (mean, median, modus), dan pengukuran variasi kelompok (rentang data, varians, standar deviasi) (Sugiyono, 2017). Mahasiswa harus memahami jenis data dan cara menyajikan data agar data yang dimiliki dapat tergambarkan dengan jelas bagi peneliti maupun orang lain dan tidak terjadi kesalahan atau kesulitan dalam menggunakan statistik (Sugiyono, 2017). Pemahaman ini penting untuk membangun pemahaman konsep statistik lainnya, seperti konsep atas ukuran-ukuran yang menjelaskan suatu data, menjadi pondasi untuk bernalar dan berpikir (Ben-Zvi \& Garfield, 2004), bahkan untuk keperluan publikasi ilmiah (Weissgerber et al., 2016; Weissgerber et al., 2015). Hal tersebut juga dapat menjadi penilaian atas kemampuan mahasiswa untuk memahami pentingnya menyajikan data dengan baik dan tepat sehingga data tersebut memiliki makna dan dapat dijelaskan ke dalam hal yang lebih spesifik.

Statistik deskriptif di atas sebenarnya sudah dikenalkan dalam pembelajaran statistik namun kadang mengalami kesulitan dalam memahami konsep statistik tertentu, seperti yang berkaitan dengan ukuran pemusatan dan penyebaran (Garfield \& Ben-Zvi, 2007; Dewi dkk, 2020; Saidi \& Siew, 2018). Kesulitan lain adalah dalam menganalisis dan menginterpretasi data yang disajikan dalam grafik atau diagram (Wahyuningrum, Rahayu \& Meiliasari, 2014; Glancy et al., 2017). Penilaian pengetahuan dan pemahaman dalam mempelajari statistik juga hanya didasari atas permasalahan yang ada di buku, seperti tentang perhitungan-perhitungan statistik, bukan dari sisi cara mereka memahami dan bernalar yang menerapkan ide-ide statistik ke dalam penyelesaian permasalahan statistik (Garfield, 2003). Setiap kesalahan, hambatan, maupun situasi pembelajaran statistik yang terjadi di sekolah pada akhirnya cenderung menjadi implikasi atas permasalahan pembelajaran statistik di perguruan tinggi (Fernández-Chamorro et al., 2020; Nikiforidou, Lekka \& Pange, 2010). Kondisi ini seringkali menjadi suatu evaluasi pembelajaran statistik di bangku perkuliahan. Mahasiswa ternyata masih belum sepenuhnya memahami pentingnya statistik untuk penelitian dan kehidupan (Chiesi et al., 2016; Retnawati et al., 2019). Pengetahuan mereka dalam menyajikan data secara visual juga hanya sebatas mengetahui prosedur, bukan memahami kegunaannya. Delmas et al. (2007) menemukan bahwa kebanyakan mahasiswa memilih bentuk penyajian data tanpa memahami kegunaannya maupun kesesuaiannya dengan konteks masalah. Selain itu, banyak mahasiswa juga merasa bahwa statistik sulit untuk dipelajari sehingga menimbulkan sikap dan ekspektasi negatif ketika berhadapan dengan statistik (McGrath, 2014; Paul \& Cunnington, 2017).

Berdasarkan permasalahan di atas, penyelidikan pemahaman mahasiswa pendidikan biologi dalam mempelajari biostatistika perlu dilakukan, khususnya pemahaman terkait statistik deskriptif yang berupa penyajian representasi visual data penelitian. Ini dikarenakan pemahaman statistik deskriptif dapat mempengaruhi cara mahasiswa memahami statistik sebagai alat bantu dalam menyelesaikan permasalahan maupun penelitian (Idris \& Yang, 2017; Libman, 2010). Penyajian data secara visual itu juga menjadi kebutuhan dalam melakukan analisis data (Garfield et al., 2008) sehingga mahasiswa tidak hanya dituntut untuk mengetahui prosedur membuat grafik, tetapi juga memahami informasi yang mereka sajikan. Friel, Curcio \& Bright (2001) selanjutnya mendefinisikan hal tersebut sebagai "graph sense" yang menunjukkan bahwa representasi visual dapat mencerminkan tentang bagaimana seseorang memproses data kuantitatif yang dimiliki untuk dijadikan informasi yang memiliki makna. Suatu representasi grafis yang dibuat tentunya dapat menyajikan beragam informasi yang bisa digali atau diinterpretasikan. Kegiatan ini pada dasarnya 
dilakukan agar data atau informasi mudah untuk dipahami dan menarik perhatian orang lain untuk membacanya (Friel et al., 2001; Strasser, 2007; Sugiyono, 2017) sehingga mahasiswa perlu memahami keterkaitan konteks suatu data dengan bentuk penyajian datanya. Representasi visual yang dibuat juga membutuhkan ketelitian dan ketepatan agar data yang disajikan tidak memberikan informasi yang menyesatkan (Strasser, 2007).

\section{METODE PENELITIAN}

Metode penelitian yang digunakan adalah kualitatif deskriptif (Sugiyono, 2019; Maxwell, 2008). Adapun penelitian ini berfokus pada jenisjenis kesalahan mahasiswa dalam membuat representasi visual data statistik pada mata kuliah biostatistika. Penelitian tersebut dilakukan kepada 79 mahasiswa semester 4 yang sedang mengambil mata kuliah biostatistika di salah satu universitas swasta di Jakarta, Indonesia. Mereka pada mulanya sudah dibekali pengetahuan tentang berbagai macam grafik untuk menyajikan suatu data statistik berupa histogram, poligon frekuensi, ogive, diagram batang, diagram lingkaran, dan diagram garis. Mahasiswa diberikan konteks berupa data statistik pembelajaran biologi, lalu diminta untuk menyajikan data tersebut ke dalam bentuk penyajian data yang sesuai.

Berikut ini diberikan skor disposisi berpikir kreatif siswa kelas VII SMP X pada pelajaran IPA (Biologi) di Jakarta Selatan Tahun Pelajaran 2016/2017.

\begin{tabular}{|c|c|c|c|}
\hline No. Resp. & Skor & No. Resp. & Skor \\
\hline 1 & 108 & 26 & $95+\mathrm{c}$ \\
\hline 2 & $100+\mathrm{a}$ & 27 & $94+\mathrm{a}$ \\
\hline 3 & $95+\mathrm{b}$ & 28 & 128 \\
\hline 4 & $99+\mathrm{c}$ & 29 & 114 \\
\hline 5 & $110+\mathrm{a}$ & 30 & $100+\mathrm{c}$ \\
\hline 6 & $120-\mathrm{b}$ & 31 & 95 \\
\hline 7 & $91+\mathrm{a}+\mathrm{b}$ & 32 & $95+\mathrm{b}+\mathrm{a}$ \\
\hline 8 & $94+\mathrm{c}$ & 33 & 98 \\
\hline 9 & $101+\mathrm{b}$ & 34 & 93 \\
\hline 10 & $103+\mathrm{b}$ & 35 & $97+\mathrm{b}$ \\
\hline 11 & $115+\mathrm{c}$ & 36 & 109 \\
\hline 12 & $95+\mathrm{a}+\mathrm{c}$ & 37 & 112 \\
\hline 13 & $97+\mathrm{b}+\mathrm{c}$ & 38 & 119 \\
\hline 14 & $98+\mathrm{c}$ & 39 & $128-\mathrm{a}-\mathrm{c}$ \\
\hline 15 & $99+\mathrm{a}$ & 40 & 130 \\
\hline 16 & $100-\mathrm{a}$ & 41 & $122-\mathrm{a}$ \\
\hline 17 & 102 & 42 & $115-\mathrm{b}$ \\
\hline 18 & 99 & 43 & $117-\mathrm{c}$ \\
\hline 19 & $98+\mathrm{c}$ & 44 & $118+\mathrm{a}$ \\
\hline 20 & 90 & 45 & $101+\mathrm{c}$ \\
\hline 21 & 103 & 46 & $105+\mathrm{b}$ \\
\hline 22 & 105 & 47 & $108+\mathrm{c}$ \\
\hline 23 & $111-\mathrm{b}$ & 48 & $100+\mathrm{b}$ \\
\hline 24 & $118-\mathrm{a}$ & 49 & $111+\mathrm{b}$ \\
\hline 25 & $121-\mathrm{c}$ & 50 & $122-\mathrm{c}$ \\
\hline
\end{tabular}

Gambar 1. Data yang diberikan kepada mahasiswa

Adapun konteks yang diberikan adalah data skor disposisi berpikir kreatif siswa kelas VII SMP $\mathrm{X}$ pada pelajaran IPA (Biologi) di Jakarta Selatan, seperti yang ditunjukkan pada Gambar 1. Data tersebut dibuat secara khusus, yakni dengan adanya variabel yang harus diisi dan dihitung berdasarkan tiga angka terakhir di Nomor Pokok Mahasiswa (NPM), sehingga setiap mahasiswa memiliki data yang berbeda. Ini bertujuan agar mahasiswa bisa mengerjakan secara mandiri. Mahasiswa selanjutnya diminta untuk menyajikan data yang mereka miliki ke dalam grafik. Mereka harus memindai hasil pekerjaan mereka tersebut dan dikumpulkan dalam bentuk PDF.

Representasi visual dianalisis dengan teknik analisis deskriptif yang tertuju pada pemenuhan prinsip dasar penyajian data (komunikatif dan lengkap) serta kesesuaian data yang disajikan dengan representasi visualnya. Analisis ini juga mengacu pada beberapa perilaku yang terkait dengan "graph sense" oleh Friel et al. (2001), yaitu (1) kemampuan untuk mengenali setiap komponen pada grafik, hubungan antar komponen, dan pengaruh komponen pada penyajian informasi dalam grafik, (2) kemampuan untuk mengutarakan informasi di dalam grafik yang berkaitan dengan konteks, (3) kemampuan untuk memahami hubungan antara tabel, grafik, dan data yang ingin dianalisis, serta (4) kemampuan untuk mengenali kesesuaian grafik atas data yang ingin disajikan.

\section{HASIL DAN PEMBAHASAN}

Hasil dari pekerjaan mahasiswa menunjukkan bahwa sebagian besar mahasiswa, yakni sebanyak $54,43 \%$, ternyata masih melakukan kesalahan dalam menyajikan representasi visual data dengan grafik. Ada beberapa jenis kesalahan yang terjadi ketika mahasiswa menyajikan data dengan histogram, poligon frekuensi, ogive, diagram batang, diagram lingkaran, maupun diagram garis. Tabel 1 memperlihatkan tentang banyaknya mahasiswa berdasarkan kesalahan pada tiap jenis grafik atau diagram. Bentuk penyajian data berupa histogram, poligon frekuensi, dan ogive pada dasarnya merupakan pengetahuan baru bagi mahasiswa sehingga masih banyak mahasiswa yang melakukan kesalahan. Mahasiswa sebenarnya lebih familiar terhadap diagram batang, lingkaran, maupun garis karena sudah pernah dipelajari di bangku sekolah, namun faktanya adalah mahasiswa ternyata juga mengalami kesulitan dan melakukan beberapa kesalahan.

Mahasiswa pada umumnya sudah mengetahui bahwa data yang mereka miliki berjumlah 50 responden sehingga harus disajikan ke dalam tabel distribusi frekuensi terlebih dahulu. Data pada tabel tersebut juga disajikan dalam bentuk grafik 
untuk menampilkan sisi komunikatif dalam menyajikan data (Sugiyono, 2017). Adapun kesalahan mahasiswa mulai terlihat ketika data disajikan ke dalam grafik.

Tabel 1. Banyaknya mahasiswa berdasarkan kesalahan di setiap jenis grafik atau diagram

\begin{tabular}{cccccc}
\hline & \multicolumn{4}{c}{ Jenis Grafik atau Diagram } \\
\cline { 2 - 6 } & $\begin{array}{c}\text { Histogram dan } \\
\text { Poligon Frekuensi }\end{array}$ & Ogive & $\begin{array}{c}\text { Diagram } \\
\text { Batang }\end{array}$ & $\begin{array}{c}\text { Diagram } \\
\text { Lingkaran }\end{array}$ & $\begin{array}{c}\text { Diagram } \\
\text { Garis }\end{array}$ \\
\cline { 2 - 6 } $\begin{array}{c}\text { Banyak Mahasiswa yang } \\
\text { Melakukan Kesalahan }\end{array}$ & 15 & 27 & 9 & 30 & 13 \\
\hline
\end{tabular}

\section{Kesalahan dalam memberikan keterangan atau menyampaikan informasi}

Jenis kesalahan ini merupakan kesalahan yang mengindikasikan kurangnya pemahaman mahasiswa tentang keterangan yang harus dicantumkan pada bentuk penyajian data yang dibuat. Kesalahan tersebut bisa berupa tidak tepatnya keterangan yang disampaikan maupun kesalahan meletakkan informasi.

\begin{tabular}{c|c|c|c|}
\hline Skor & $\begin{array}{c}\text { frekuensi } \\
\text { Kumulatif } \\
\left\langle\left(f \text { kum }^{*}\right)\right.\end{array}$ & Skor & $\begin{array}{l}\text { Frekuensi } \\
\text { Kumulatif } \\
>(f \text { kum } * x)\end{array}$ \\
\hline$<90$ & 0 & $>90$ & 50 \\
$<96$ & 5 & $>96$ & 45 \\
$<102$ & 21 & $>102$ & 29 \\
$<108$ & 29 & $>108$ & 21 \\
$<114$ & 36 & $>114$ & 14 \\
$<120$ & 45 & $>120$ & 5 \\
$<126$ & 47 & $>126$ & 3 \\
$<132$ & 50 & $>132$ & 0 \\
\hline
\end{tabular}

Skor Disposisi Berpikir Kreatif

Siswa Kelas VII SMP $x$ paaa Pelajaran IPA (Biologi)

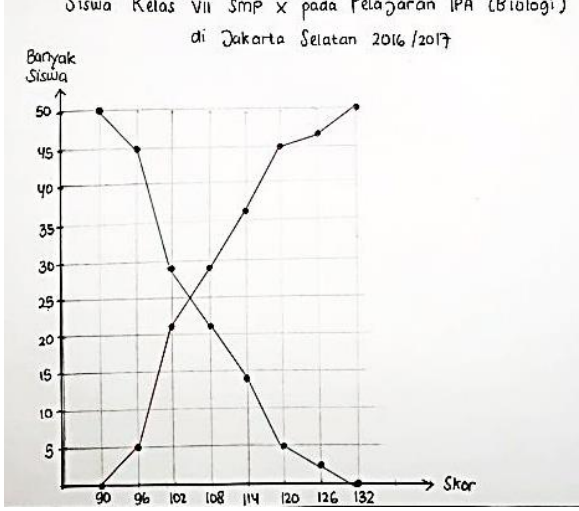

Gambar 2. Cara mahasiswa menyajikan data dengan ogive

Gambar 2 memperlihatkan bahwa mahasiswa menuliskan keterangan pada sumbu-y secara kurang tepat ketika membuat ogive. Mahasiswa mengetahui prosedur bahwa penyajian data dengan ogive memerlukan informasi frekuensi kumulatif, seperti pada gambar 2 atas, namun keterangan tersebut tidak dicantumkan di dalam ogive mereka (gambar 2 bawah). Ini menjadikan informasi atas data yang diperoleh tidak tersampaikan dengan jelas. Representasi visual yang dibuat menjadi tidak lengkap, padahal kelengkapan merupakan prinsip dasar dalam menyajikan data (Sugiyono, 2017). Ketika mahasiswa hanya menuliskan konteks frekuensi biasa tanpa menegaskan bahwa itu adalah frekuensi kumulatif, artinya mahasiswa dapat dikatakan belum menyadari penggunaan ogive untuk menyajikan data. Kondisi ini berkaitaan dengan kemampuan dalam mengenali dan memahami komponen yang ada pada ogive yang nantinya akan mengarah pada kesesuaian representasi visual dengan konteks (Friel et al., 2001). Kesalahan yang teridentifikasi tersebut mungkin terlihat sederhana, namun berimplikasi pada penyampaian informasi. Ogive menerangkan distribusi frekuensi kumulatif sehingga penyampaian datanya ditujukan untuk menampilkan keterkaitan antara setiap nilai batas kelas dengan dengan frekuensi kumulatifnya (Hasan, 2012).

Ketika mahasiswa menyajikan data dengan ogive, kesalahan penyampaian informasi juga teridentifikasi mulai dari tabel yang mereka buat, yakni pemahaman tentang frekuensi kumulatif itu sendiri. Gambar 3 memperlihatkan bahwa mahasiswa salah menuliskan bagian frekuensi kumulatif ketika skor menunjukkan kurang dari 90. Frekuensi tersebut seharusnya diisi dengan nol karena data yang kurang dari 90 memang tidak ada. Mahasiswa juga tidak menambah batas kelas terbawah, yaitu skor 132, sehingga prosedur pembuatan ogive negatif menjadi kurang tepat. Ini mengindikasikan bahwa mahasiswa belum menyadari keterkaitan antara makna keterangan pada tabel, konteks data, dan representasi visualnya. Informasi yang diutarakan pada tabel maupun grafik tidak sesuai dengan konteks yang ada. 


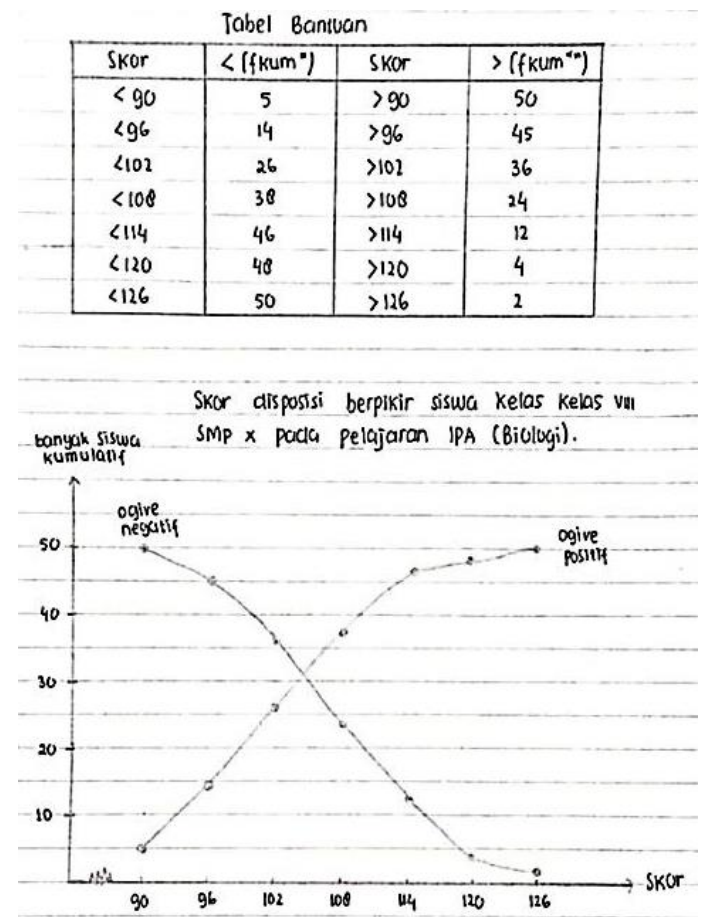

Gambar 3. Kesalahan mahasiswa pada tabel bantuan membuat ogive

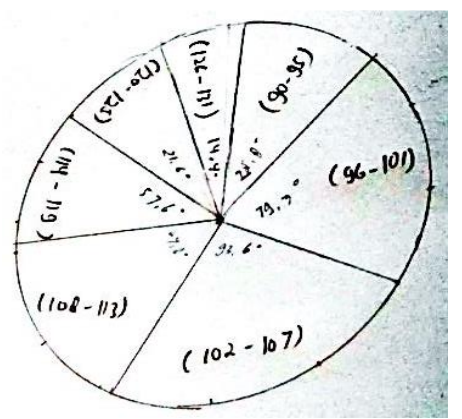

\begin{tabular}{|c|c|}
\hline Stors & $\begin{array}{l}\text { Frekuens: } \\
\text { Presentass: } \\
\text { \% }\end{array}$ \\
\hline $90-95$ & $10 \times 3.6$ \\
\hline $96-101$ & $18 \times 36$ \\
\hline $102-107$ & $24 \times 3,6$ \\
\hline $100-113$ & $24 \times 3.6$ \\
\hline $149-189$ & $12 \times 7.5$ \\
\hline $120-125$ & $8 \times 2,6$ \\
\hline $126-131$ & $4 \times 3 \times 16$ \\
\hline
\end{tabular}

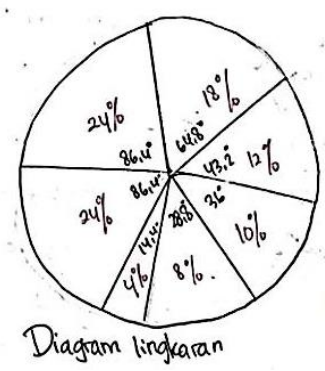

Gambar 4. Beberapa representasi visual mahasiswa dengan diagram lingkaran

Adapun kesalahan lainnya berupa kesalahan meletakkan informasi, seperti yang terjadi ketika mahasiswa menyajikan data dengan diagram lingkaran pada Gambar 4. Tidak adanya judul dan kesalahan meletakkan informasi membuat diagram tersebut kehilangan prinsip dasar penyajian data. Pembaca juga akan kehilangan informasi tentang hal yang sebenarnya ingin disampaikan. Gambar 4 pada dasarnya menunjukkan bahwa mahasiswa mencantumkan derajat di setiap juring lingkaran. Beberapa mahasiswa menyampaikan informasi derajat tersebut beserta konteks data yang berupa skor siswa (gambar 4 atas), sedangkan mahasiswa lainnya menyampaikan informasi derajat yang disertai dengan persentasenya (gambar 4 bawah). Ini mengindikasikan mahasiswa belum menyadari bahwa derajat hanya sebagai alat bantu untuk membuat juring atau bagian-bagian lingkaran yang sesuai dengan data.

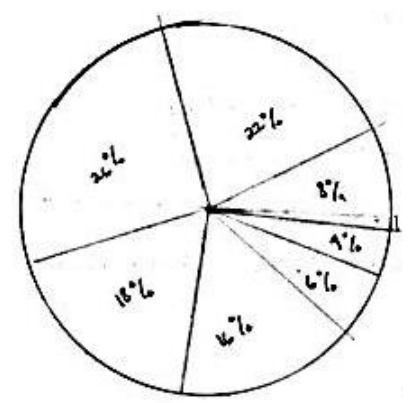

Gambar 5. Kurangnya informasi pada diagram lingkaran yang disajikan

Mahasiswa lainnya (Gambar 5) bahkan hanya memunculkan persentase tanpa menyampaikan kepemilikan persentase tersebut. Kondisi ini menunjukkan bahwa mahasiswa belum menyadari dan memahami informasi yang seharusnya ditampilkan pada grafik yang nantinya akan dilihat oleh orang lain atau pembaca. Mereka belum mengarahkan ke sudut pandang para pembaca diagram. Mahasiswa hanya memikirkan teknis pembuatan saja tanpa memaknai bentuk penyajian data yang dibuat sehingga informasi yang disajikan bukan merupakan kebutuhan untuk para pembaca. Informasi yang seharusnya disajikan adalah nama kelompok data dengan persentasenya (Hasan, 2012) sehingga diagram ini dapat memvisualisasikan kuantitas antar kelompok dengan besaran bagiannya melalui persentase.

Ragam kesalahan yang teridentifikasi di atas pada dasarnya menunjukkan bahwa penulisan keterangan yang tepat dan jelas merupakan hal yang perlu diperhatikan. Ini bertujuan agar suatu grafik tersebut komunikatif dan lengkap (Sugiyono, 2017) sehingga data penelitian tersampaikan dan mudah dipahami oleh pembaca. Kesesuaian keterangan sebagai informasi suatu konteks juga menjadi pemahaman yang seharusnya dimiliki karena itu merupakan salah satu kemampuan ketika berhadapan dengan grafik 
(Friel et al., 2001) sehingga grafik bukan hanya sebatas tampilan gambar, tetapi juga sebagai bentuk representasi penyampaian beragam pesan atau informasi.

\section{Kesalahan dalam memahami konsep matematis yang ada pada grafik}

Kesalahan ini dapat dikategorikan sebagai kesalahan menyesuaikan bentuk grafik dengan pemahaman matematis mahasiswa. Kondisi tersebut pada dasarnya berfokus pada konsep matematis yang memang menjadi prasyarat dalam mempelajari statistik (McGrath, 2014; Mulhern \& Wylie, 2006). Mahasiswa tidak hanya dilatih untuk mengetahui prosedur, tetapi juga dituntut untuk memahami cara merepresentasikan perhitungan data ke dalam gambar-gambar. Gambar 6 dapat memperlihatkan adanya kesalahan yang terjadi ketika mahasiswa hanya mengetahui prosedur penyajian data dengan diagram lingkaran, namun tidak memahami hubungan antara persentase yang sudah mereka hitung dengan juring-juring lingkaran yang mereka bentuk. Mereka pada dasarnya mengetahui prosedur bahwa data yang telah dinyatakan dalam persen dikalikan dengan $3,6^{\circ}$ guna mendapatkan luas juring dalam derajat, lalu hasil persentase ditampilkan pada diagram. Langkah ini sebenarnya didasari atas hubungan konsep luas satu lingkaran dalam derajat dengan persen, yakni $360^{\circ} \div 100 \%=3,6^{\circ}$ (Sugiyono, 2017) sehingga ini bisa diterapkan untuk mencari juring lingkaran. Ketika pengetahuan ini tidak diimbangi dengan pemahaman konsep matematis, maka penyajian informasi menjadi salah. Gambar 6 (atas) menunjukkan bahwa juring $40 \%$ lebih kecil dibandingkan juring $16 \%$, begitu juga bagian yang lainnya, sedangkan Gambar 6 memperlihatkan bahwa mahasiswa tidak mempedulikan total persentase yang ada pada satu lingkaran, tidak memahami maksud dari persentase tersebut, dan tidak menyadari besarnya satu bagian terhadap bagian yang lain. Kondisi ini mempengaruhi prinsip komunikatif (Sugiyono, 2017) dalam penyajian data karena informasi menjadi tidak tersampaikan dengan baik dan membingungkan para pembaca. Informasi tersebut akhirnya dikatakan tidak sesuai dengan konteks yang sebenarnya terjadi.
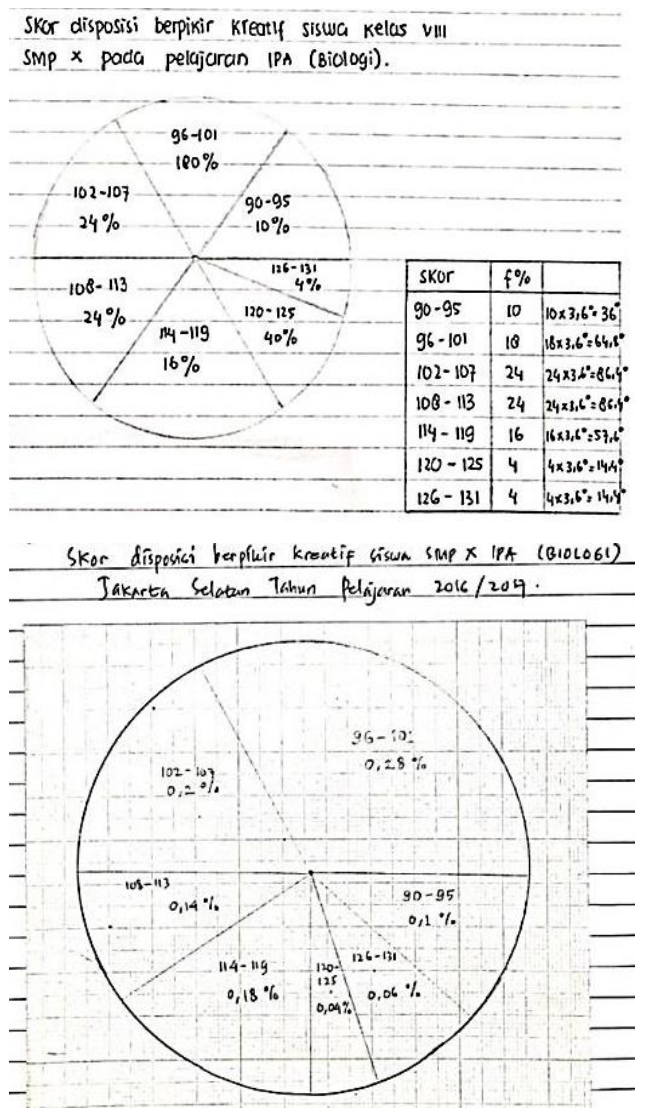

Gambar 6. Representasi visual mahasiswa dengan diagram lingkaran

Kesalahan yang didasari atas latar belakang pemahaman matematis juga dapat dilihat ketika mahasiswa membuat grafik yang membutuhkan sistem koordinat Kartesius. Skala di setiap sumbu suatu grafik merupakan hal yang perlu diperhatikan (Sugiyono, 2017; Holcomb, 2016) karena dapat mempengaruhi pemahaman informasi atas visualisasi yang dibentuk. Gambar 7 memperlihatkan bahwa mahasiswa tidak menyajikan skala yang tepat pada sumbu- $y$ ketika menyajikan data dengan histogram dan poligon frekuensi maupun diagram batang. Mereka sebenarnya mencoba menyajikan bilangan dengan selisih yang sama, namun mereka menggunakan bilangan permulaan yang kurang tepat dan belum memahami perbedaan jarak yang mereka gunakan. 

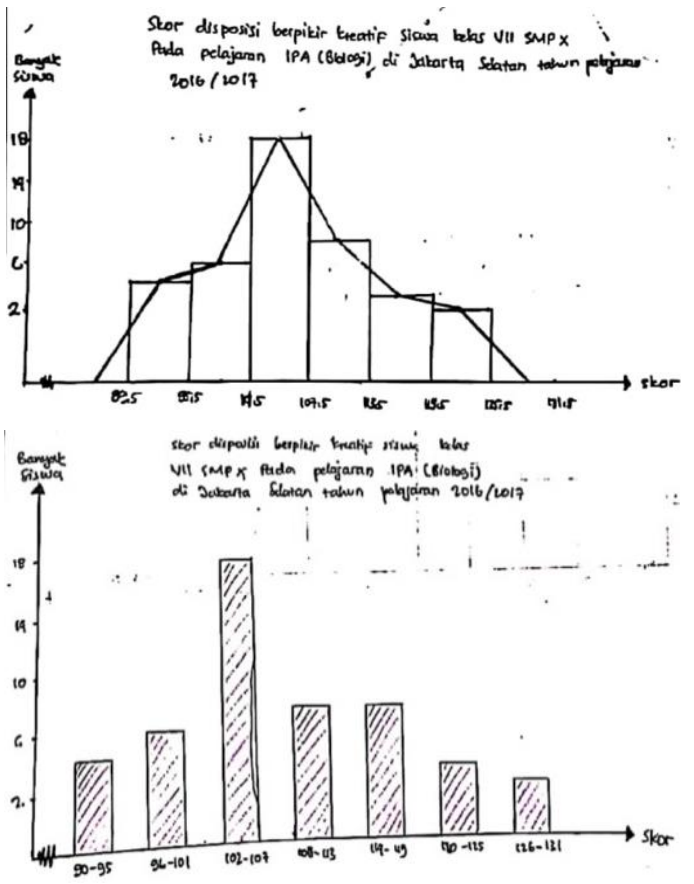

Gambar 7. Representasi visual mahasiswa dengan histogram, poligon frekuensi, dan diagram batang

Jenis kesalahan yang berhubungan dengan konsep matematis ini dapat menjadi penilaian tentang kemampuan untuk mengenali dan memahami komponen yang ada pada grafik (Friel et al., 2001). Perhitungan dasar yang memerlukan ketelitian dan kenyamanan dalam besaran numerik memang menjadi prasyarat penting ketika menangani data kuantitatif (Mulhern \& Wylie, 2006; Delmas et al., 2007). Setiap komponen dan bentuknya akan memberikan pemahaman atas analisis statistik serta dapat menghadirkan berbagai interpretasi (Weissgerber, 2015) sehingga proses pembuatan representasi visual yang memerlukan kemampuan matematis tersebut menjadi hal yang harus dipahami dengan baik dan dilakukan dengan teliti.

\section{Kesalahan memaknai bilangan yang tercantum pada grafik}

Kesalahan ini diartikan sebagai kesalahan dalam memahami bilangan sebagai konteks. Ini didasari atas pemahaman bahwa data yang tersaji ke dalam bilangan itu merupakan suatu konteks yang dapat menyampaikan informasi atas beberapa fenomena atau mengomunikasikan dan menyelesaikan permasalahan (Moore, 1998; Idris \& Yang, 2017). Kesalahan tersebut dapat terlihat seperti pada Gambar 8 yang menunjukkan adanya ketidakpahaman mahasiswa pada bilanganbilangan yang mereka cantumkan dalam grafik.
Mahasiswa terlihat mengetahui prosedur penyajian data dengan histogram, namun mereka belum memahami maksud dari penggunaan tepi kelas interval yang seharusnya ditempatkan di garisgaris batang. Ketika suatu data disajikan dengan histogram, sumbu yang mendatar seharusnya menyatakan kelas interval (Hasan, 2012) yang biasanya disajikan dengan tepi kelas interval karena batangnya yang saling melekat. Ketidakpahaman ini menjadikan mahasiswa menempatkan bilangan tersebut di bagian batang yang lain, bukan di tiap ujung batang. Kondisi demikian juga menunjukkan bahwa mahasiswa belum memahami keterkaitan antara bilangan dengan jenis representasi visual, seperti penggunaan tepi kelas pada histogram, nilai tengah pada poligon frekuensi, atau batas bawah interval kelas pada ogive.

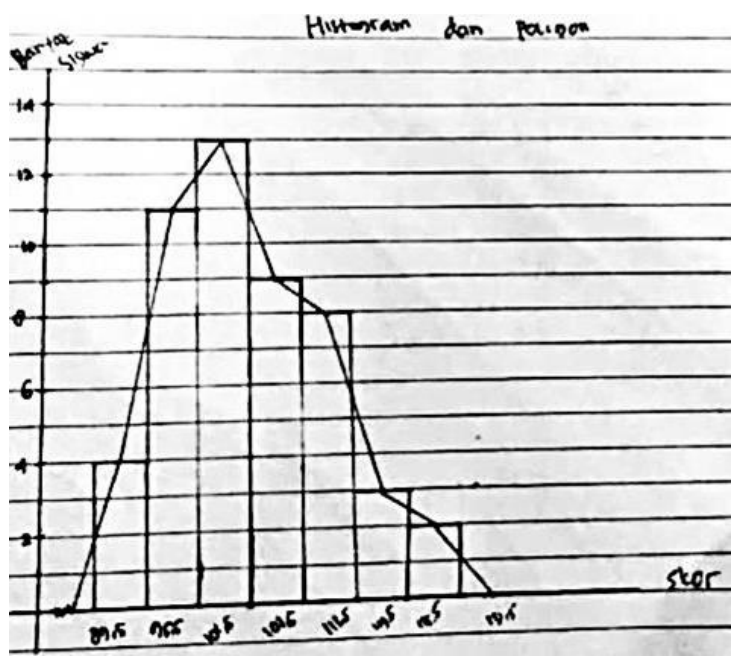

Gambar 8. Kesalahan penempatan skor dalam histogram

Kesalahan jenis ini juga ditunjukkan pada Gambar 9 ketika mahasiswa menyajikan data dengan diagram lingkaran. Frekuensi persentatif yang sudah dicari ternyata berbeda dengan yang dicantumkan pada diagram. Mahasiswa terlihat belum memahami makna bilangan-bilangan yang disajikan dalam persen tersebut yang menjadi suatu informasi bagi pembaca. Mahasiswa juga dapat dikatakan belum memahami keterkaitan antara prosedur dengan diagram yang disajikan.

Adapun kesalahan jenis ini juga tergambarkan ketika mahasiswa menyajikan data dengan diagram garis. Suatu data kelompok akan menampilkan kelas-kelas interval. Setiap kelas tersebut tentunya memiliki frekuensinya masing-masing. Kalaupun itu disajikan dalam diagram garis, setiap titik seharusnya mewakili sebuah kelas interval. 
Kondisi ini ternyata belum dipahami oleh mahasiswa sehingga beberapa mahasiswa hanya memunculkan nilai batas bawah, seperti pada Gambar 10. Representasi visual tersebut pada akhirnya memberikan informasi suatu data tunggal, bukan data kelompok. Ketidakpahaman ini juga ditunjukkan pada Gambar 9, yakni mahasiswa tampak bingung untuk menempatkan informasi di sumbu- $x$ sehingga menuliskan lebih dari satu kategori yang berupa kelas interval dan nilai tengah atas konteks skor disposisi berpikir kreatif siswa.

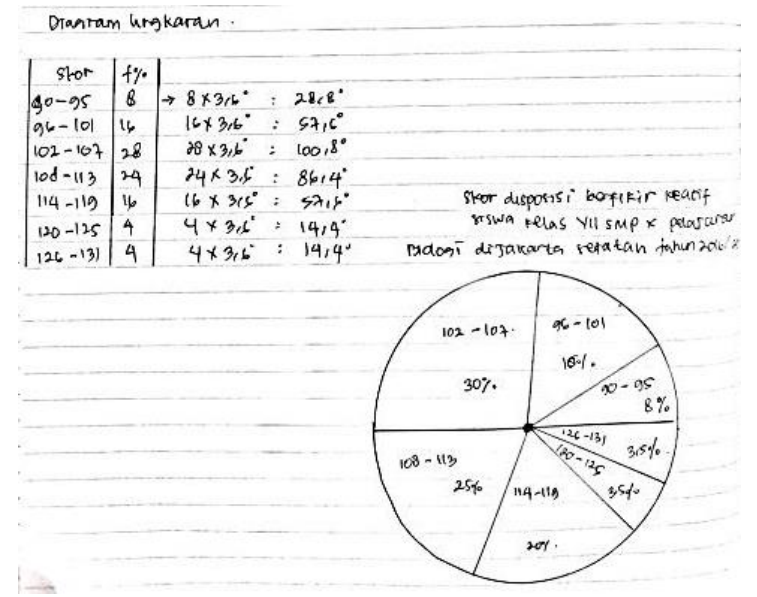

Gambar 9. Kesalahan menyajikan persentase dalam diagram lingkaran

Setiap kesalahan yang terjadi mengindikasikan bahwa representasi visual yang dibuat belum sepenuhnya memenuhi prinsip komunikatif. Informasi yang disajikan dapat membingungkan para pembaca dan tidak tersampaikan dengan baik. Hal ini juga dapat memperlihatkan kemampuan mahasiswa dalam mengenali dan memahami setiap komponen pada grafik (Friel, Curcio \& Bright, 2001) untuk menunjukkan makna representasi visual dengan konteks. Mahasiswa perlu memahami arti dari bilangan-bilangan yang mereka dapatkan ketika tersaji di dalam tabel maupun grafik. Pemahaman ini diperlukan agar mereka mengerti tujuan suatu representasi visual (Weissgerber, 2016) serta menyadari bahwa data bukan sekadar bilangan, tetapi informasi yang memiliki makna (Sugiyono, 2017). Penggeneralisasian, prediksi, atau pengidentifikasian suatu kecenderungan juga memerlukan kemampuan untuk menghubungkan informasi yang ada pada grafik ke dalam konteks situasinya (Friel et al., 2001).
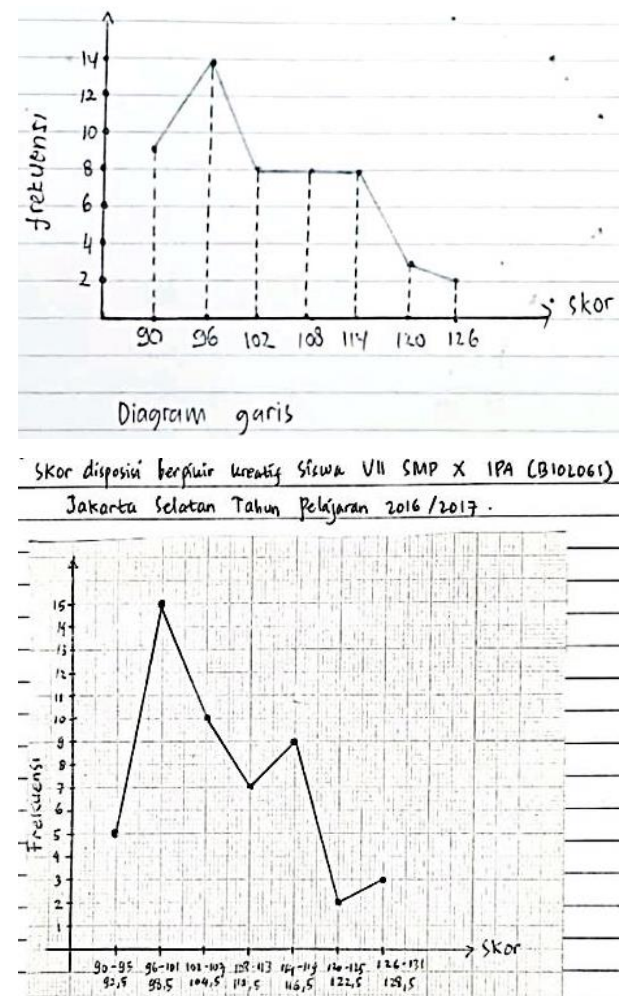

Gambar 10. Penyajian diagram garis untuk data skor siswa

\section{Kesalahan memilih grafik yang sesuai dengan tujuan penyajian data}

Kesalahan ini berkaitan dengan kesadaran tentang hubungan antara bentuk representasi dengan informasi yang ingin disampaikan. Grafik yang dibuat tentunya memiliki tujuan yang dapat menggambarkan situasi berdasarkan konteks data, misalnya penyajian data dengan diagram garis dimaksudkan agar pembaca dapat melihat perkembangan suatu keadaan, sedangkan diagram batang atau diagram lingkaran dapat digunakan untuk membandingkan suatu kelompok (Sugiyono, 2017; Hasan, 2012). Hal ini menunjukkan bahwa representasi visual perlu disesuaikan dengan konteks data dan tujuannya.

Konteks data yang berupa skor disposisi berpikir kreatif siswa pada dasarnya dikelompokkan ke dalam kelas-kelas interval untuk dilihat seberapa banyak siswa yang mendapatkan skor pada interval tertentu. Hal ini dapat menjadi gambaran tentang kemampuan disposisi berpikir kreatif siswa yang dapat dilihat berdasarkan batasan skor. Apabila kondisi tersebut disajikan dengan representasi visual, maka tujuannya bukan tertuju pada perkembangan keadaan pada suatu kurun waktu tertentu sehingga konteks data ini kurang sesuai jika disajikan dengan diagram garis. Adapun kenyataannya 
adalah masih banyak mahasiswa yang menggambarkan diagram garis, seperti yang ditunjukkan pada gambar 11. Mahasiswa belum menyadari bahwa naik-turunnya garis pada diagram garis tersebut menjadi kurang bermakna. Kondisi ini membuat diagram tersebut menjadi kurang komunikatif.

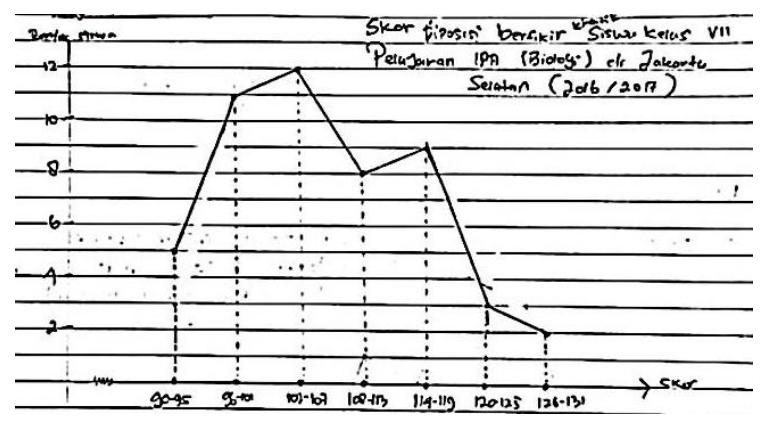

Gambar 11. Penyajian diagram garis untuk data kelompok

Kemampuan mahasiswa di atas selanjutnya menjadi penilaian atas kemampuan untuk mengenali kesesuaian grafik terhadap tujuan yang ingin tersampaikan berdasarkan konteks data (Friel, Curcio \& Bright, 2001). Mahasiswa perlu menyadari dan memahaminya dengan baik agar setiap komponen pada representasi visual tidak menjadi sia-sia. Ketika berkenaan dengan penyajian data maupun publikasi ilmiah, hal ini juga menjadi suatu sorotan bahwa perlu ada pemahaman tentang kapan sebaiknya menggunakan tabel atau grafik, bagaimana memilih grafik yang benar sesuai dengan jenis data, ukuran sampel, dan desain penelitian, serta bagaimana menetapkan grafik yang sesuai dengan jenis distribusi datanya (Weissgerber, 2016). Beberapa mahasiswa sebenarnya ada yang menyadari ketidakcocokkan konteks data dengan diagram garis tersebut, namun mereka ternyata tidak bisa menjelaskan alasannya, seperti pada Gambar 11. Mereka hanya menilai bahwa konteks data yang dimiliki tidak cocok sehingga menghindari pembuatan diagram garis.

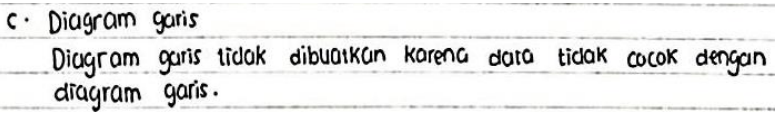

Gambar 12. Alasan mahasiswa tentang tidak dibuatnya diagram garis

\section{KESIMPULAN}

Kesalahan mahasiswa yang teridentifikasi ketika menyajikan representasi visual data statistik diklasifikasikan sebagai kesalahan dalam memberikan keterangan atau menyampaikan informasi, kesalahan dalam memahami konsep matematis yang ada pada grafik, kesalahan memaknai bilangan yang tercantum pada grafik, dan kesalahan memilih grafik yang sesuai dengan tujuan penyajian data. Representasi visual yang dibuat masih banyak yang belum memenuhi prinsip dasar penyajian data. Mereka juga belum sepenuhnya memiliki kemampuan untuk mengenali dan memahami komponen yang ada pada grafik maupun keterkaitan setiap komponen dengan konteks data. Setiap jenis kesalahan yang terjadi ini selanjutnya dapat menjadi gambaran tentang pemahaman mahasiswa terhadap statistik yang pada dasarnya harus diterapkan pada penelitian mereka di bidang kependidikan biologi atau biologi murni.

\section{DAFTAR PUSTAKA}

Ben-Zvi, D., \& Garfield, J. (2004). Statistical Literacy, Reasoning, and Thinking: Goals, Definitions, and Challenges. In: Ben-Zvi D., Garfield J. (eds) The Challenge of Developing Statistical Literacy, Reasoning and Thinking. Springer,

Dordrecht. https://doi.org/10.1007/1-4020-2278-6_1

Brown, C., Illian, J. B., \& Burslem, D. F. R. P. (2016). Success of spatial statistics in determining underlying process in simulated plant communities. Journal of Ecology, 104(1), 160-172. https://doi.org/10.1111/13652745.12493

Chiesi, F., Primi, C., Bilgin, A. A., Lopez, M. V., del Carmen Fabrizio, M., Gozlu, S., \& Tuan, N. M. (2016). Measuring University Students' Approaches to Learning Statistics: An Invariance Study. Journal of Psychoeducational Assessment, 34(3), 256-268. https://doi.org/10.1177/0734282915596125

Dani BZ., \& Joan G. (2004) Statistical Literacy, Reasoning, and Thinking: Goals, Definitions, and Challenges.

Delmas, R. C., Garfield, J. B., Ooms, A., \& Chance, B. L. (2007). Assessing students' conceptual understanding after a first course in statistics. Statistics Education Research Journal, 6(2), 28-58. http://eprints.kingston.ac.uk/21003/

Dewi, D. K., Khodijah, S. S., \& Zanthy, L. S. (2020). Analisis kesulitan matematik siswa SMP pada materi statistika. Jurnal Cendekia:

Wahyuningrum. Analisis Kesalahan Mahasiwa EduBiologia Volume 1 Number 1 Januari 2021 
Jurnal Pendidikan Matematika, 4(1), 1-7. https://doi.org/10.31004/cendekia.v4i1.148

Fernández-Chamorro, V., Pamplona, S., \& PérezFructuoso, M. J. (2020). Assessing prior knowledge of statistics in students attending an online university. Journal of Computing in Higher Education, 32(1), 182-202. https://doi.org/10.1007/s12528-019-09236-9

Friel, S. N., Curcio, F. R., \& Bright, G. W. (2001). Making sense of graphs. Journal for Research in Mathematics Education, 32(2), 124-158. https://vis.arc.vt.edu/ npolys/projects/safas/74 9671.pdf\%5Cnhttps://snoid.sv.vt.edu/ npolys/ projects/safas/749671.pdf

Garfield, J. B. (2003). Assessing Statistical Reasoning. Statistics Education Research Journal (SERJ). MSOR Connections, 2(1).

Garfield, J. B., Ben-Zvi, D., Chance, B., Medina, E., Roseth, C., \& Zieffler, A. (2008). Developing students' statistical reasoning: Connecting research and teaching practice. Developing Students' Statistical Reasoning: Connecting Research and Teaching Practice, April 2016, 1-408. https://doi.org/10.1007/9781-4020-8383-9

Garfield, J., \& Ben-Zvi, D. (2007). How students learn statistics revisited: A current review of research on teaching and learning statistics. International Statistical Review, 75, 372-396.

Glancy, A. W., Moore, T. J., Guzey, S., \& Smith, K. A. (2017). Students' successes and challenges applying data analysis and measurement skills in a fifth-grade integrated STEM unit. Journal of Pre-College Engineering Education Research, 7(1), 68-75. https://doi.org/10.7771/2157-9288.1159

Hasan, I. M. (2012). Pokok-pokok Materi Statistik 1 (Statistik Deskriptif) Edisi Kedua. PT Bumi Aksara: Jakarta.

Hayat, M. J., Powell, A., Johnson, T., \& Cadwell, B. L. (2017). Statistical methods used in the public health literature and implications for training of public health professionals. PLOS ONE, 12(6), 1-10. https://doi.org/10.1371/journal.pone.0179032

Hidayat, A. (2018). Kemampuan biostatistik melalui pendekatan inverstigasi pada materi regresi sederhana. Syntax Literate: Jurnal Ilmiah Indonesia, 3(3), 1-11.

Holcomb, Z. C. (2016). Fundamentals of descriptive statistics. Routledge.

Idris, K., \& Yang, K. L. (2017). Development and validation of an instrument to measure Indonesian pre-service teachers' conceptions of statistics. Asia-Pacific Education Researcher, 26(5), 281-290.

Lachenbruch, P. A. (2011). Department of Statistics Papers Teaching Biostatistics to Postgraduate Students in Public Health.

Libman, Z. (2010). Integrating real-life data analysis in teaching descriptive statistics: a constructivist approach. Journal of Statistics Education, 18(1).

Loux, T. M., Varner, S. E., \& vanNatta, M. (2016). Flipping an introductory biostatistics course: A case study of student attitudes and confidence. Journal of Statistics Education, 24(1), 1-7.

Maxwell, J. A. (2008). Designing a qualitative study. The SAGE handbook of applied social research methods, 2, 214-253.

McGrath, A. L. (2014). Content, affective, and behavioral challenges to learning: students' experiences learning statistics. International Journal for the Scholarship of Teaching and Learning, 8(2).

McGreevy, K. M., \& Church, F. C. (2020). Active learning: Subtypes, intra-exam comparison, and student survey in an undergraduate biology course. Education Sciences, 10(7), 1-15. https://doi.org/10.3390/educsci10070185.

Moore, D. S. (1998). Statistics among the liberal arts. Journal of the American Statistical Association, 93(444), 1253-1259. https://doi.org/10.1080/01621459.1998.104737 86

Mulhern, G., \& Wylie, J. (2006). Mathematical prerequisites for learning statistics in psychology: assessing core skills of numeracy and mathematical reasoning among undergraduates. Psychology Learning \& Teaching, 5(2), 119-132. https://doi.org/10.2304/plat.2005.5.2.119

Nikiforidou, Z., Lekka, A., \& Pange, J. (2010). Statistical literacy at university level: the current trends. Procedia-Social and Behavioral Sciences, 9 9, 795-799. https://doi.org/10.1016/j.sbspro.2010.12.236

Oster, R. A., Devick, K. L., Thurston, S. W., Larson, J. J., Welty, L. J., Nietert, P. J., Pollock, B. H., Pomann, G.-M., Spratt, H., Lindsell, C. J., \& Enders, F. T. (2020). Learning gaps among statistical competencies for clinical and translational science learners. Journal of Clinical and Translational Science, 1-11. https://doi.org/10.1017/cts.2020.498

Panzeri, S., Harvey, C. D., Piasini, E., Latham, P. E., \& Fellin, T. (2017). Cracking the neural code for sensory perception by combining statistics, 
intervention, and behavior. Neuron, 93(3), 491507. https://doi.org/10.1016/j.neuron.2016.12.036

Paul, W., \& Cunnington, R. C. (2017). An exploration of student attitudes and satisfaction in a gaise-influenced introductory statistics course. Statistics Education Research Journal, 16(2), 487-510.

Retnawati, H., Apino, E., Djidu, H., Ningrum, W. P., Anazifa, R. D., \& Kartianom, K. (2019). Scaffolding for international students in statistics lecture. Journal of Physics: Conference $\quad$ Series, $\quad$ 1320(1). https://doi.org/10.1088/17426596/1320/1/012078

Rivest, L., \& Duchesne, T. (2016). A general angular regression model for the analysis. Appl. Statist., 65(3), 445-463.

Saidi, S. S., \& Siew, N. M. (2018). Assessing students' understanding of the measures of central tendency and attitude towards statistics in rural secondary schools. International Electronic Journal of Mathematics Education, 14(1), 73-86. https://doi.org/10.12973/iejme/3968

Sayeg-Sanchez, G., \& Rodriguez-Paz, M. X. (2020). Performance of college students in a statistics course using mastery learning. IEEE Global Engineering Education Conference, EDUCON, 2020-April, 746-751. https://doi.org/10.1109/EDUCON45650.2020. 9125122

Siegel, S. (1986). Statistik Nonparamterik untuk Ilmu-ilmu Sosial. Diterjemahkan oleh Suyuti, Z., \& Simatupang, Z. dalam koordinasi Hagul, P. Gramedia: Jakarta.
Soraggi, S., Wiuf, C., \& Albrechtsen, A. (2018). Powerful inference with the D-statistic on lowcoverage whole-genome data. G3: Genes, Genomes, Genetics, 8(2), 551-566. https://doi.org/10.1534/g3.117.300192

Strasser, N. (2007). Avoiding statistical mistakes. Journal of College Teaching \& Learning (TLC), 4(7), 51-58. https://doi.org/10.19030/tlc.v4i7.1565

Sugiyono. (2017). Statistika untuk Penelitian. Alfabeta: Bandung.

Sugiyono. (2019). Metode Penelitian Pendidikan (Kuantitatif, Kualitatif, Kombinasi, $R \& D$ dan Penelitian Pendidikan. Alfabeta: Bandung.

Wahyuningrum, A. S., Rahayu, W., \& Meiliasari. (2014). Mengembangkan kemampuan berpikir statistik siswa SMP Kelas VII pada materi bentuk penyajian data statistik dengan pendidikan matematika realistik Indonesia (PMRI). Prosiding Seminar Nasional Pendidikan Matematika 2014. Program Studi Pendidikan Matematika, Fakultas Keguruan dan Ilmu Pendidikan, Universitas Islam Sultan Agung, Semarang.

Weissgerber, T. L., Garovic, V. D., Milin-Lazovic, J. S., Winham, S. J., Obradovic, Z., Trzeciakowski, J. P., \& Milic, N. M. (2016). Reinventing biostatistics education for basic scientists. PLoS Biology, 14(4), 2-13. https://doi.org/10.1371/journal.pbio.1002430

Weissgerber, T. L., Milic, N. M., Winham, S. J., \& Garovic, V. D. (2015). Beyond bar and line graphs: time for a new data presentation paradigm. PLoS Biology, 13(4), 1-10. https://doi.org/10.1371/journal.pbio.1002128. 